\title{
Association between Serum 25-Hydroxyvitamin D Level and Rheumatoid Arthritis
}

\author{
Xiaomin Cen, ${ }^{1}$ Yuan Liu, ${ }^{2}$ Geng Yin, ${ }^{1}$ Min Yang, ${ }^{1}$ and Qibing Xie ${ }^{1}$ \\ ${ }^{1}$ Department of Rheumatology and Immunology, West China Hospital, Sichuan University, Chengdu, Sichuan 610041, China \\ ${ }^{2}$ Department of Rheumatology and Immunology, First Affiliated Hospital of Xiamen University, Xiamen, Fujian 361003, China
}

Correspondence should be addressed to Qibing Xie; qibingxie@126.com

Received 3 December 2014; Revised 21 January 2015; Accepted 27 January 2015

Academic Editor: Long Shen

Copyright (C) 2015 Xiaomin Cen et al. This is an open access article distributed under the Creative Commons Attribution License, which permits unrestricted use, distribution, and reproduction in any medium, provided the original work is properly cited.

The objective of this study is to examine and evaluate whether serum 25(OH)D is associated with disease activity in patients with rheumatoid arthritis (RA). Our results suggested that serum $25(\mathrm{OH}) \mathrm{D}$ in RA groups has significant lower level (35.99 \pm $12.59 \mathrm{nmol} / \mathrm{L})$ than that in the normal groups $(54.35 \pm 8.20 \mathrm{nmol} / \mathrm{L}, P<0.05)$. Based on the DAS28, patients with RA were divided into four subgroups, and no differences were found in the four groups $(P>0.05)$. The $25(\mathrm{OH}) \mathrm{D}$ levels in complete remission, low disease activity, middle disease activity, and high disease activity group were $32.86 \pm 12.26,33.97 \pm 13.28,38.41 \pm 10.64$, and $38.94 \pm 13.35 \mathrm{nmol} / \mathrm{L}$, respectively. Based on the serum 25(OH)D levels, patients with RA were divided into inadequate group and normal group, and there were no significant differences in baseline characteristics and disease activity in the two groups. Our results showed that serum 25(OH)D levels in the inadequate group are significantly lower than those in the normal group. However, no correlations were found between 25(OH)D levels and disease activity among 116 patients with RA. The present findings will help to understand the association between $25(\mathrm{OH}) \mathrm{D}$ and disease activity of RA.

\section{Introduction}

Vitamin D has important functions in physiological processes, and vitamin $\mathrm{D}$ deficiency may play a role in pathophysiological processes and has increasingly been recognized as an important human health problem. 25-hydroxyvitamin D $[25(\mathrm{OH}) \mathrm{D}]$, the accepted measure of vitamin D status, has been linked to several pathological states, including cardiovascular diseases, inflammatory disease, and high allcause mortality in the general population [1]. Recent studies showed that $25(\mathrm{OH}) \mathrm{D}$ not only regulates calcium and phosphorus metabolism, but also plays a role in regulating immune and anti-inflammatory activities by adjusting growth and differentiation of macrophages, dendritic cells, T lymphocytes, and B lymphocytes, inhibiting inflammatory factors such as TNF- $\alpha$, and promoting generation of antiinflammatory factors such as IL-4 and IL-10 [2, 3].

Rheumatoid arthritis (RA) is a chronic inflammatory autoimmune disease characterized by synovitis. The aetiology and pathogenesis of RA remain obscure and many factors may be associated with its pathogenesis. $25(\mathrm{OH}) \mathrm{D}$ has immunoregulatory activities, so it is an important factor that may increase the prevalence of many autoimmune diseases such as RA and systemic lupus erythematosus [4, 5]. Increasing findings also supported that low or deficient levels of $25(\mathrm{OH}) \mathrm{D}$ may be associated with an increased risk for the development of RA [5-7]. Recently, the role of vitamin D deficiency in the pathogenesis of RA, as well as the relationship between vitamin D deficiency and the activity of RA, is discussed [8]. However, several studies have demonstrated a significant negative correlation between serum $25(\mathrm{OH}) \mathrm{D}$ levels and the activity of RA [6, 9-12]. Moreover, no correlation between serum 25(OH)D levels and the activity of RA was also observed in some reports [13-15]. Although these controversies still have not shown whether $25(\mathrm{OH}) \mathrm{D}$ deficiency is a primary phenomenon or an outcome of RA, these findings will help to understand the association between $25(\mathrm{OH}) \mathrm{D}$ and disease activity of RA. Thus, the objective of this study was performed to analyze the $25(\mathrm{OH}) \mathrm{D}$ levels in RA patients and healthy people and investigate the association between the serum levels of $25(\mathrm{OH}) \mathrm{D}_{3}$ and disease activity of RA patients from Southwest China. 


\section{Methods}

2.1. General Data. RA patients $(n=116)$ and normal people $(n=50)$ were collected and admitted to Department of Rheumatology and Immunology, West China Hospital of Sichuan University, from June 2013 to December 2013. Participants were initially screened by telephone, and full assessments were conducted only for participants who did not report any exclusion criteria during the telephone screening. All participants provided written informed consent approved by the Hospital Human Research Ethics Committee of West China Hospital. All the cases included in the research were checked in by strict diagnosis standard. They were divided into two groups, the normal $(n=50)$ and RA $(n=116)$ group. The RA group includes 93 female and 23 male patients with RA diagnosed by Department of Rheumatology and Immunology, West China Hospital of Sichuan University. The control group includes 40 females and 10 males, which has no significant differences on sex and age with the RA group.

2.2. Inclusion and Exclusion Standards. Patients with RA in the clinical trials should be up to the standard as follows: (1) those who meet the diagnosis standard and modified classification of the American College of Rheumatology (ACR, 1987) [16] and (2) those who are beyond 18 years old. Patients with any of the following phenotypes should be excluded out of the clinical trials: (1) those who do not meet the diagnostic and modified classification standard; (2) those who are not beyond 18 years old; (3) those who have systemic lupus erythematosus, Sjogren syndrome, and other connective diseases; (4) those who have a damage in cardiovascular system, lung, kidney, and/or other organs.

2.3. Baseline Analysis. Clinical data of patients in the RA group were collected, including gender, age, height, weight, course of disease, swollen joint count, tender joint count, duration of morning stiffness, patient activity scale, $\mathrm{C}$ reactive protein (CRP), erythrocyte sedimentation rate (ESR), and rheumatoid factor (RF). Body mass index (BMI) and Disease Activity Score-28 (DAS28) of RA patients were calculated. Basic data of participants in the control group were collected, including gender, age, weight, and height, and BMI of each participant was calculated.

2.4. Analysis of Serum 25(OH)D Concentration. $3 \mathrm{~mL}$ fasting blood samples of each participant in the RA and normal groups were centrifuged. Serum was applied for the measurement of $25(\mathrm{OH}) \mathrm{D}$ concentration using enzyme-linked immunosorbent (ELISA) method. The vitamin D kit of the British Immunodiagnostic Systems (IDS) was used. Correlation of $25(\mathrm{OH}) \mathrm{D}$ and disease activity of RA in the RA and control groups was analyzed. Moreover, RA group was divided into four subgroups according to DAS28 score, and further explore the association of between the values of DAS28 score and $25(\mathrm{OH}) \mathrm{D}$ levels in RA patients. According to the $25(\mathrm{OH}) \mathrm{D}$ levels, patients of RA were divided into reduced group $(<50 \mathrm{nmol} / \mathrm{L})$ and normal group
TABLE 1: Participant characteristics of patients in the RA and control groups.

\begin{tabular}{lccc}
\hline Variable & RA & Controls & $P$ value \\
\hline Age (years) & $50.1 \pm 10.9$ & $48.1 \pm 10.3$ & 0.283 \\
Ratio of female : male & $93: 23$ & $40: 10$ & 0.980 \\
Weight $(\mathrm{kg})$ & $57.5 \pm 9.0$ & $58.1 \pm 8.0$ & 0.686 \\
Height $(\mathrm{cm})$ & $160.9 \pm 6.4$ & $161.6 \pm 6.1$ & 0.568 \\
BMI $\left(\mathrm{kg} / \mathrm{m}^{2}\right)$ & $22.2 \pm 2.9$ & $22.2 \pm 2.1$ & 0.970 \\
\hline
\end{tabular}

( $>50 \mathrm{nmol} / \mathrm{L}$ ). The association between clinical data and disease activity in two groups was analyzed to explore the correlation of these parameters and $25(\mathrm{OH}) \mathrm{D}$ level.

2.5. Statistical Analysis. Statistical analysis was carried out using SPSS Version 19.0 for Windows. Data are presented as mean or median. The continuous variables that fit the Gaussian distribution were compared by using the independent samples $t$ test, and the other parameters are compared by using the chi-square test. $P$ values lower than 0.05 were regarded as statistically significant difference.

\section{Results}

3.1. Baseline Characteristics. Participant characteristics of patients in the RA and control groups were shown in Table 1. In the RA group, a total of 116 patients with the average age of $50.1 \pm 10.9$ years were included in this study, and the ratio of male and female was $1: 4.04$. The average height was $160.9 \pm$ $6.4 \mathrm{~cm}$, the average body weight was $57.5 \pm 9 \mathrm{~kg}$, and the mean body mass index (BMI) was $22.2 \pm 2.9 \mathrm{~kg} / \mathrm{m}^{2}$. In the control group, their average age was $48.1 \pm 10.3$ years, the ratio of male and female was $1: 4$, their average height was $161.6 \pm 6.1 \mathrm{~cm}$, the average body weight was $58.1 \pm 8 \mathrm{~kg}$, and the mean BMI was $22.2 \pm 2.1 \mathrm{~kg} / \mathrm{m}^{2}$. These results showed that there were no reliable differences in age, gender, height, body weight, and BMI in two groups $(P>0.05)$.

3.2. 25(OH)D Levels in the RA and Control Groups. Table 2 presents the clinical characteristics of the study subjects according to the level of 25(OH)D. As shown in Table 2, $25(\mathrm{OH}) \mathrm{D}$ levels of the peripheral blood in the RA groups were lower than those in the control groups $(P<0.05)$. The percentage of $25(\mathrm{OH}) \mathrm{D}$ less than $25 \mathrm{nmol} / \mathrm{L}$ in the RA groups was significantly higher than those in the control groups (22.4\% versus $0, P<0.05$, Table 2$)$. The percentage of 25(OH)D from 25 to less than $50 \mathrm{nmol} / \mathrm{L}$ was 2.13 -fold higher in the RA groups than those in the control groups $(63.8 \%$ versus $20 \%, P<0.05$, Table 2 ). However, the percentage of $25(\mathrm{OH}) \mathrm{D}$ with higher than $50 \mathrm{nmol} / \mathrm{L}$ in the RA groups was significantly lower than those in the control groups $(13.8 \%$ versus $70 \%, P<0.05$, Table 2 ). These results indicated that the percentage of patients with vitamin $\mathrm{D}$ inadequate and deficiency in the RA group was significantly higher than those in the control group, and there were statistically significant differences $(P<0.05)$. 
TABle 2: Distribution of 25-hydroxyvitamin D level in the RA and control groups.

\begin{tabular}{lccc}
\hline 25(OH)D level & RA $(n=116)$ & Controls $(n=50)$ & $P$ value \\
\hline Tested level $(\mathrm{nmol} / \mathrm{L})$ & $35.99 \pm 12.59$ & $54.35 \pm 8.20$ & $<0.05$ \\
Deficiency $(\leq 25 \mathrm{nmol} / \mathrm{L})$ & $26(22.4 \%)$ & $0(0)$ & $<0.05$ \\
Insufficiency $(25-50 \mathrm{nmol} / \mathrm{L})$ & $74(63.8 \%)$ & $15(30 \%)$ & $<0.05$ \\
Normal level $(\geq 50 \mathrm{nmol} / \mathrm{L})$ & $16(13.8 \%)$ & $35(70 \%)$ & $<0.05$ \\
\hline
\end{tabular}

TABLE 3: Differences of level of 25(OH)D in peripheral blood of four subgroups in the RA group.

\begin{tabular}{lcc}
\hline Subgroups & Vitamin D level $(\mathrm{nmol} / \mathrm{L})$ & $P$ value $^{*}$ \\
\hline DAS28 $<2.6$ & $32.86 \pm 12.26$ & $>0.05$ \\
$2.6 \leq$ DAS $28<3.2$ & $33.97 \pm 13.28$ & $>0.05$ \\
$3.2 \leq$ DAS $28 \leq 5.1$ & $38.94 \pm 13.35$ & $>0.05$ \\
DAS28 $>5.1$ & $38.41 \pm 10.64$ & $>0.05$ \\
\hline
\end{tabular}

${ }^{*} P$ values were obtained from the comparison of $25(\mathrm{OH}) \mathrm{D}$ levels among the subgroups.

3.3. $25(\mathrm{OH}) D$ Levels in the RA Subgroups. Based on the Disease Activity Score-28 (DAS28), these patients with RA were stratified into four subgroups as follows: complete remission (DSA28 < 2.6), low disease activity $(2.6 \leq$ DAS $28<$ $3.2)$, moderate disease activity $(3.2 \leq \mathrm{DAS} 28 \leq 5.1)$, and high disease activity (DAS28 > 5.1). Table 3 shows the differences of $25(\mathrm{OH}) \mathrm{D}$ levels in peripheral blood of four subgroups patients. As shown in Table 3, the 25(OH)D levels of complete remission, low disease activity, middle disease activity, and high disease activity groups were $32.86 \pm 12.26,33.97 \pm$ $13.28,38.41 \pm 10.64$, and $38.94 \pm 13.35 \mathrm{nmol} / \mathrm{L}$, respectively. No significant differences were observed between complete remission and low disease activity group. Similar results were also found between middle disease activity and high disease activity group.

3.4. Comparison Analysis of RA Patients with 25(OH)D Deficiency and Normal Level Groups. Based on the 25(OH)D levels, these patients with RA were divided into 25(OH)D deficiency $(n=100)$ and normal $(n=16)$ groups. Table 4 showed the results of comparison analysis of RA patients with 25(OH)D deficiency and normal groups. As shown in Table 4, there were no significant differences in age, sex, height, weight, BMI, disease duration, swelling and tenderness joint count, duration of morning stiffness, visual analogue scale (VAS), C-reactive protein (CRP), erythrocyte sedimentation rate (ESR), rheumatoid factor (RF), and DAS28 score $(P>$ $0.05)$.

\section{Discussion}

RA is a chronic inflammatory autoimmune disease, mainly involving joint synovial membrane causing joint deformities. RA may cause bone loss and damage around joint $[4,5]$. Reports have indicated that $90 \%$ of patients with RA symptoms will develop the radiological changes of joints damage during two years [17]. Studies have also found that T cells and cytokines play an important role in the pathogenesis of RA
[18]. 25(OH)D is one of essential steroid hormones, which is involved in bone metabolism and immune regulation. Vitamin $\mathrm{D}$ receptors exist on the $\mathrm{T}$ and $\mathrm{B}$ lymphocytes, macrophages, and dendritic cells. After $25(\mathrm{OH}) \mathrm{D}$ combined with these receptors, they will regulate cell proliferation and differentiation and further inhibit the release of inflammatory factors. Then, they will play important roles in regulation of immune responses [19]. Thus, 25(OH)D may not only improve osteoporosis symptom of patients with rheumatoid arthritis but also play an important role in the regulation of immune system.

There has been a rapid growth in interest in the role of vitamin $\mathrm{D}$ in health and disease. 25(OH)D levels have been studied in RA. Previous reports have shown that serum $25(\mathrm{OH}) \mathrm{D}$ deficiency and inadequate is found in about 34$84 \%$ and $12-52 \%$ of RA patients, respectively $[6,10-12,14,15]$. Several studies have also shown that serum 25(OH)D levels of patients with RA are significantly lower than those in the control group. Other studies reported that there were no significant differences in serum levels of $25(\mathrm{OH}) \mathrm{D}_{3}$ between RA patients and healthy controls [12, 20, 21]. These findings suggested that the proportion of patients with $25(\mathrm{OH}) \mathrm{D}$ deficiency and inadequate may be variable and related to population race, region, diet, sample size, age, sex, BMI, and other factors. In the present study, our results demonstrated that the percentages of patients with $25(\mathrm{OH}) \mathrm{D}$ deficiency and inadequate in RA group are $63.8 \%$ and $22.4 \%$, respectively. This is close to the results of Furuya et al. [11]. Moreover, our results also showed that the serum 25(OH)D levels were significantly lower in tested RA patients than those in healthy controls. There were no significant differences in age, sex, height, weight, BMI, and so forth, showing that the lower level of serum $25(\mathrm{OH}) \mathrm{D}_{3}$ may be one of risk factors in the pathogenesis of rheumatoid arthritis.

In the previous study, the association between $25(\mathrm{OH}) \mathrm{D}$ levels and disease activity of rheumatoid arthritis still remains controversial. This may stem from the fact that $25(\mathrm{OH}) \mathrm{D}$ values are easily affected by population race, region, diet, sample size, age, sex, BMI, and other factors. Some studies confirmed that the reduction of serum $25(\mathrm{OH}) \mathrm{D}$ in patients of RA was negatively correlated with clinical indexes (joint swelling, joint tenderness, ESR, etc.) and disease activity index DAS28 $[6,9-12]$. However, some reports indicated that there was no relation between $25(\mathrm{OH}) \mathrm{D}$ deficiency and disease activity in RA [13-15]. The present study suggested that no statistical difference was found among four subgroups in the RA group based on the classification of DAS28 value. Moreover, our findings also indicated that no significance between $25(\mathrm{OH}) \mathrm{D}$ deficiency and normal level groups was found under the comparison analysis of clinical parameters and 
TABLE 4: Comparison analysis of RA patients with 25(OH)D deficiency and normal levels groups ( $<50 \mathrm{nmol} / \mathrm{L})$.

\begin{tabular}{lccc}
\hline Characteristics & Deficiency $(n=100)$ & Normal level $(n=16)$ & $P$ value \\
\hline Age (years) & $49.8 \pm 10.8$ & $52.3 \pm 11.7$ & 0.684 \\
Female male ratio & $81: 19$ & $58.0 \pm 10.9$ & 0.580 \\
Weight $(\mathrm{kg})$ & $57.5 \pm 8.7$ & $162.2 \pm 7.8$ & 0.608 \\
Height $(\mathrm{cm})$ & $160.7 \pm 6.2$ & $21.9 \pm 2.3$ & 0.503 \\
BMI $\left(\mathrm{kg} / \mathrm{m}^{2}\right)$ & $22.2 \pm 3.0$ & $36.0(3,316)$ & 0.149 \\
Disease duration (months) & $43.5(3,468)$ & $4.09 \pm 1.6$ & $4.2 \pm 3.1$ \\
DAS28 & $3.5 \pm 1.8$ & $5.3 \pm 7.1$ & 0.957 \\
Patient global VAS (cm) & $3.3 \pm 3.1$ & $6.9 \pm 7.1$ & 0.779 \\
Swollen joint count $(0-28)$ & $3.9 \pm 5.4$ & $36.5(6,78)$ & 0.948 \\
Tender joint count $(0-28)$ & $5.1 \pm 6.5$ & $5.7(3.2,17.7)$ & 0.775 \\
ESR (mm/H) & $33.5(4,102)$ & $107.5(20,1900)$ \\
CRP $(\mathrm{mg} / \mathrm{L})$ & $5.1(1,78)$ & & 0.360 \\
RF $(\mathrm{IU} / \mathrm{ml})$ & $63.5(20,2220)$ & 0.595 \\
\hline
\end{tabular}

DAS28 scores in these RA patients. Based on the above results, the present findings indicated that serum $25(\mathrm{OH}) \mathrm{D}$ levels might be not associated with the disease activity of RA.

\section{Conclusion}

In summary, the present study suggested that serum $25(\mathrm{OH}) \mathrm{D}$ level might be significantly associated with the pathogenesis of RA. However, the serum values of $25(\mathrm{OH}) \mathrm{D}$ are not a good indicator of disease activity of RA patients. As serum $25(\mathrm{OH}) \mathrm{D}_{3}$ levels are not independent and/or influenced by many factors, such as region, season, and gender, further research will focus on the cross-regional and large sample to understand the association between $25(\mathrm{OH}) \mathrm{D}$ and RA in Southwest China.

\section{Conflict of Interests}

The authors declare that there is no conflict of interests regarding the publication of this paper.

\section{Authors' Contribution}

Xiaomin Cen and Yuan Liu contributed equally to this work.

\section{Acknowledgments}

This research was supported by National Natural Science Foundation of China (Grant no. 30901339 and Grant no. 81172869), the Application Foundation Project in Sichuan Province (no. 2010JY0011), and the Science and Technology Support Project of Sichuan, China (no. 2009SZ0173).

\section{References}

[1] Y. Arnson, H. Amital, and Y. Shoenfeld, "Vitamin D and autoimmunity: new aetiological and therapeutic considerations," Annals of the Rheumatic Diseases, vol. 66, no. 9, pp. 1137-1142, 2007.
[2] M. F. Holick, "Sunlight and vitamin D for bone health and prevention of autoimmune diseases, cancers, and cardiovascular disease," The American journal of Clinical Nutrition, vol. 80, no. 6, pp. 1678-1688, 2004.

[3] J. Fritsche, K. Mondal, A. Ehrnsperger, R. Andreesen, and M. Kreutz, "Regulation of 25 -hydroxyvitamin $\mathrm{D}_{3}-1 \alpha$-hydroxylase and production of $1 \alpha, 25$-dihydroxyvitamin $\mathrm{D}_{3}$ by human dendritic cells," Blood, vol. 102, no. 9, pp. 3314-3316, 2003.

[4] L. A. Merlino, J. Curtis, T. R. Mikuls, J. R. Cerhan, L. A. Criswell, and K. G. Saag, "Vitamin D intake is inversely associated with rheumatoid arthritis: results from the Iowa Women's Health Study," Arthritis \& Rheumatism, vol. 50, no. 1, pp. 72-77, 2004.

[5] K. Gopinath and D. Danda, "Supplementation of 1,25 dihydroxy vitamin D3 in patients with treatment naive early rheumatoid arthritis: a randomised controlled trial," International Journal of Rheumatic Diseases, vol. 14, no. 4, pp. 332-339, 2011.

[6] G. S. Kerr, I. Sabahi, J. S. Richards et al., "Prevalence of vitamin D insufficiency/deficiency in rheumatoid arthritis and associations with disease severity and activity," The Journal of Rheumatology, vol. 38, no. 1, pp. 53-59, 2011.

[7] A. R. Broder, J. N. Tobin, and C. Putterman, "Disease-specific definitions of vitamin $\mathrm{D}$ deficiency need to be established in autoimmune and non-autoimmune chronic diseases: a retrospective comparison of three chronic diseases," Arthritis Research \& Therapy, vol. 12, no. 5, article R191, 2010.

[8] G. G. Song, S.-C. Bae, and Y. H. Lee, "Association between vitamin D intake and the risk of rheumatoid arthritis: a metaanalysis," Clinical Rheumatology, vol. 31, no. 12, pp. 1733-1739, 2012.

[9] U. J. Haque and S. J. Bartlett, "Relationships among vitamin D, disease activity, pain and disability in rheumatoid arthritis," Clinical and Experimental Rheumatology, vol. 28, no. 5, pp. 745747, 2010.

[10] Q. Hong, J. Xu, S. Xu, L. Lian, M. Zhang, and C. Ding, "Associations between serum 25-hydroxyvitamin D and disease activity, inflammatory cytokines and bone loss in patients with rheumatoid arthritis," Rheumatology, vol. 53, no. 11, pp. 19942001, 2014.

[11] T. Furuya, T. Hosoi, E. Tanaka et al., "Prevalence of and factors associated with vitamin $\mathrm{D}$ deficiency in 4,793 Japanese patients with rheumatoid arthritis," Clinical Rheumatology, vol. 32, no. 7, pp. 1081-1087, 2013. 
[12] M. Rossini, S. M. Bongi, G. la Montagna et al., "Vitamin D deficiency in rheumatoid arthritis: prevalence, determinants and associations with disease activity and disability," Arthritis Research \& Therapy, vol. 12, no. 6, article R216, 2010.

[13] T. Baykal, K. Senel, F. Alp, A. Erdal, and M. Ugur, "Is there an association between serum 25 -hydroxyvitamin d concentrations and disease activity in rheumatoid arthritis?" Bratislava Medical Journal, vol. 113, no. 10, pp. 610-611, 2012.

[14] R. Pakchotanon, S. Chaiamnuay, P. Narongroeknawin, and P. Asavatanabodee, "The association between serum vitamin D Level and disease activity in Thai rheumatoid arthritis patients," International Journal of Rheumatic Diseases, 2013.

[15] H. J. Haga, A. Schmedes, Y. Naderi, A. M. Moreno, and E. Peen, "Severe deficiency of 25 -hydroxyvitamin $\mathrm{D}_{3}\left(25-\mathrm{OH}-\mathrm{D}_{3}\right)$ is associated with high disease activity of rheumatoid arthritis," Clinical Rheumatology, vol. 32, no. 5, pp. 629-633, 2013.

[16] F. C. Arnett, S. M. Edworthy, D. A. Bloch et al., "The American Rheumatism Association 1987 revised criteria for the classification of rheumatoid arthritis," Arthritis and Rheumatism, vol. 31, no. 3, pp. 315-324, 1988.

[17] M. Bukhari, B. Harrison, M. Lunt, D. G. I. Scott, D. P. M. Symmons, and A. J. Silman, "Time to first occurrence of erosions in inflammatory polyarthritis: results from a prospective community-based study," Arthritis \& Rheumatism, vol. 44, no. 6, pp. 1248-1253, 2001.

[18] E. Zold, P. Szodoray, J. Gaal et al., "Vitamin D deficiency in undifferentiated connective tissue disease," Arthritis Research \& Therapy, vol. 10, no. 5, article R123, 2008.

[19] M. Hewison, L. Freeman, S. V. Hughes et al., "Differential regulation of vitamin D receptor and its ligand in human monocytederived dendritic cells," Journal of Immunology, vol. 170, no. 11, pp. 5382-5390, 2003.

[20] A. D. Turhanoğlu, H. Güler, Z. Yönden, F. Aslan, A. Mansuroglu, and C. Ozer, "The relationship between vitamin D and disease activity and functional health status in rheumatoid arthritis," Rheumatology International, vol. 31, no. 7, pp. 911-914, 2011.

[21] M. Cutolo, K. Otsa, K. Laas et al., "Circannual vitamin D serum levels and disease activity in rheumatoid arthritis: Northern versus Southern Europe," Clinical and Experimental Rheumatology, vol. 24, no. 6, pp. 702-704, 2006. 


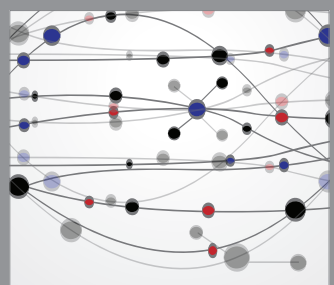

The Scientific World Journal
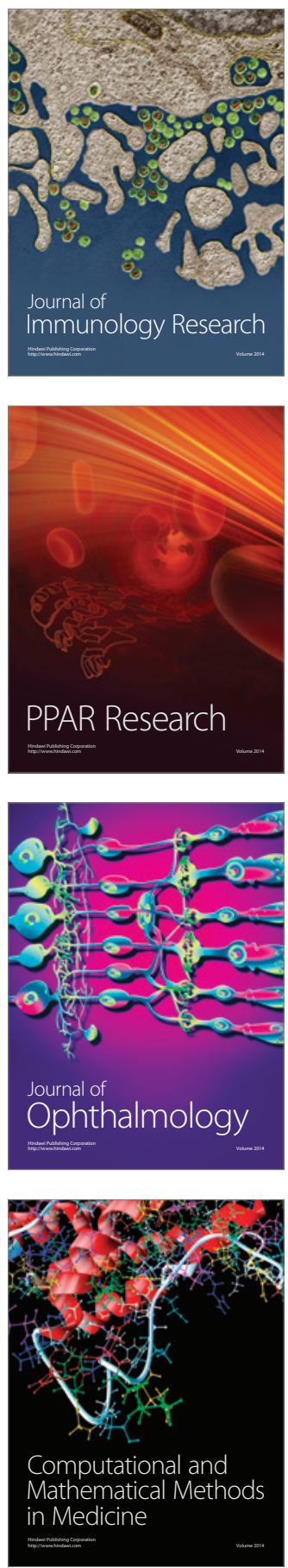

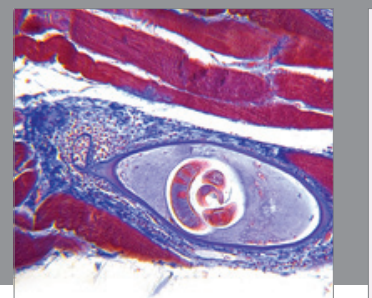

Gastroenterology

Research and Practice
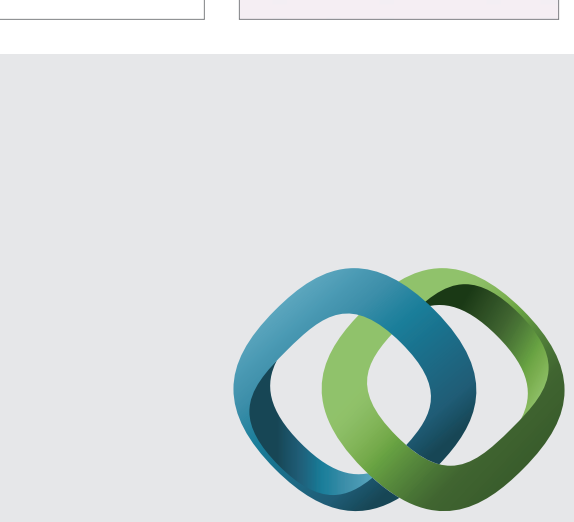

\section{Hindawi}

Submit your manuscripts at

http://www.hindawi.com
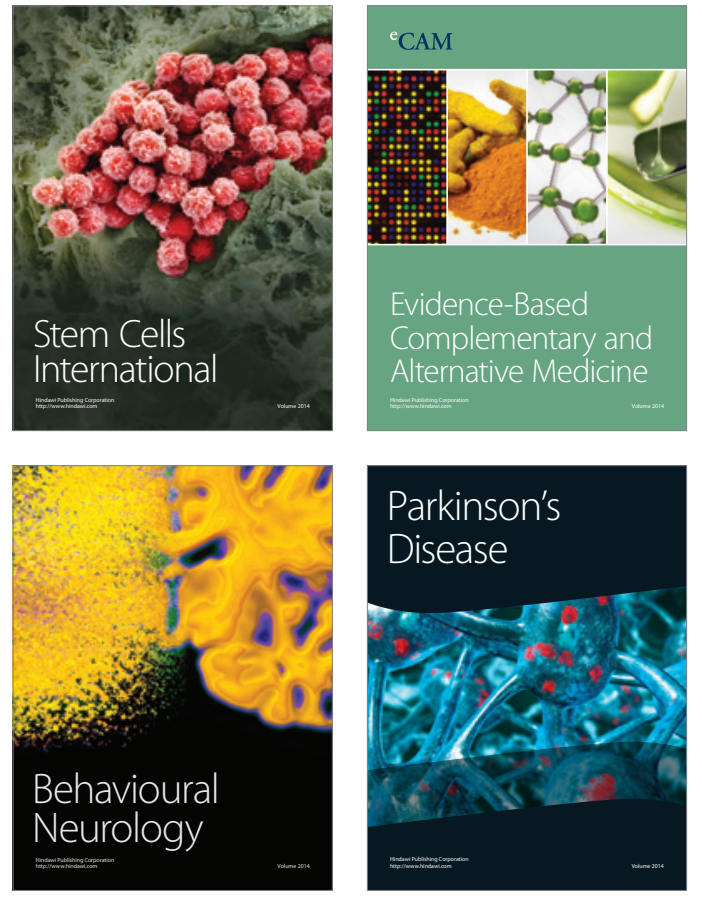
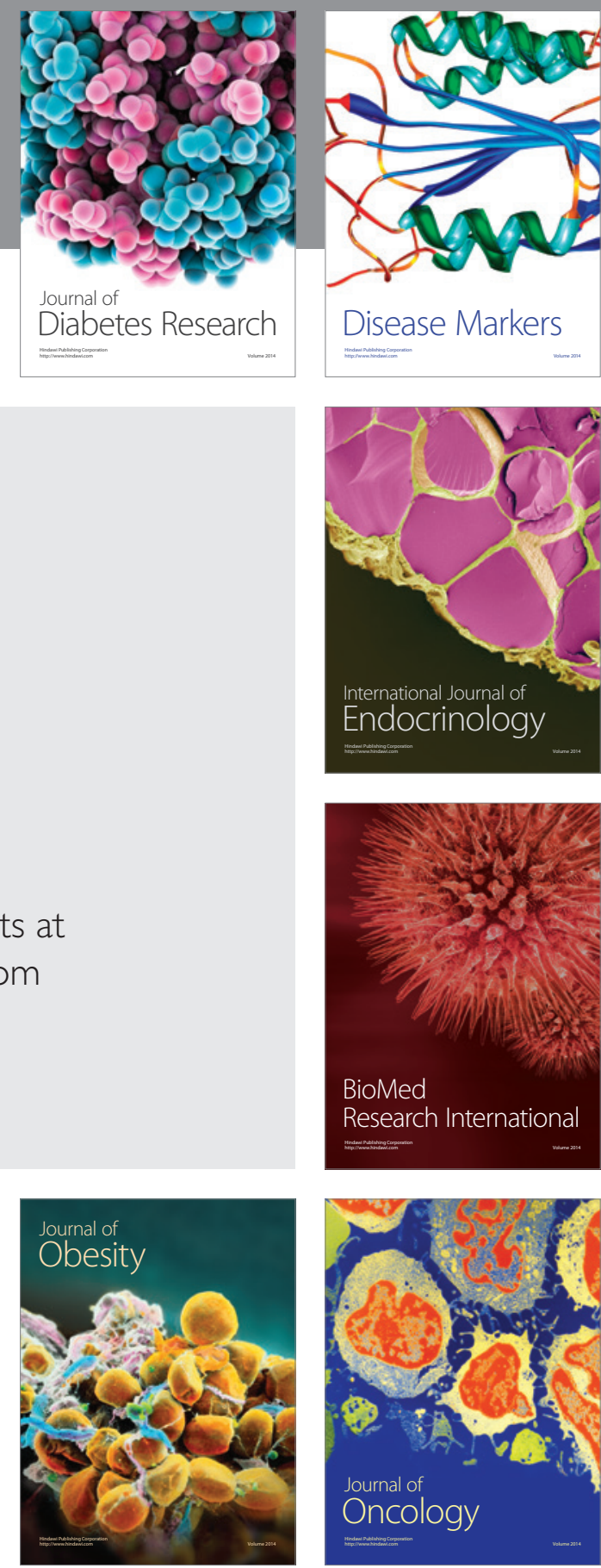

Disease Markers
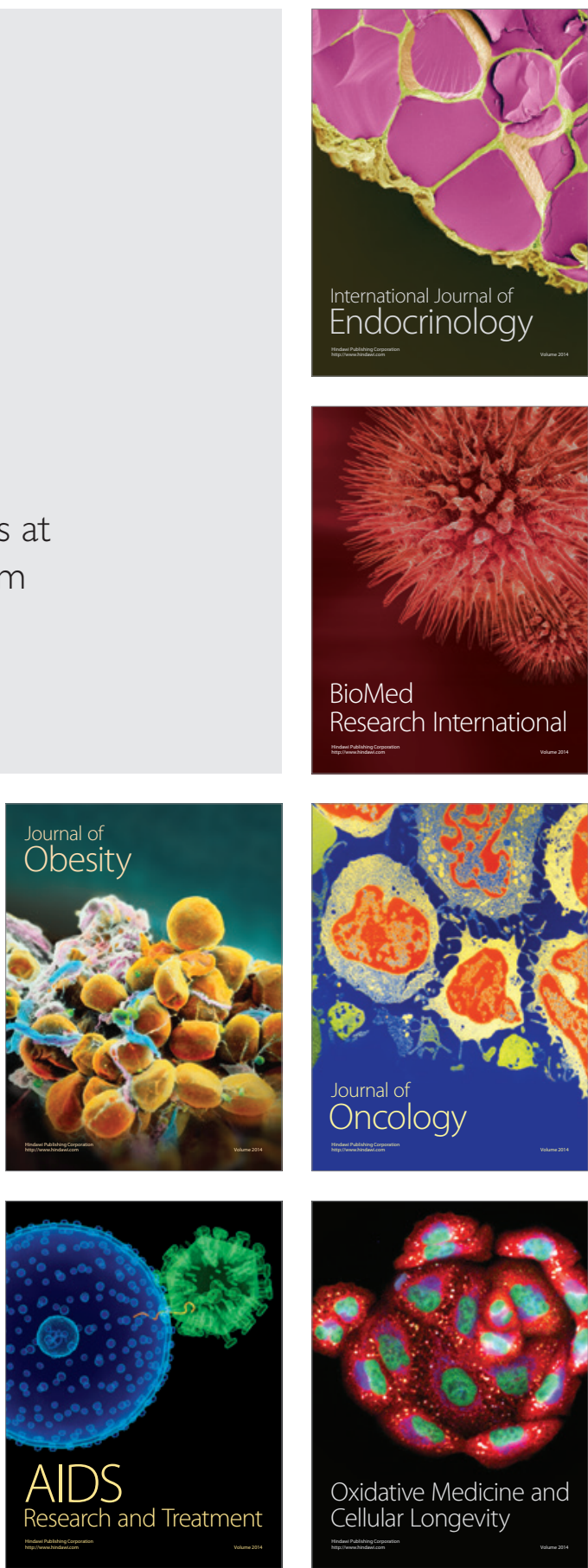